\title{
CIBERATIVISMO E COMUNIDADES VIRTUAIS: UM ESTUDO SOBRE O MOVIMENTO ANTI-GLOBO
}

\section{Tatiana Maria Bernardo da Silva}

Mestranda em Administração de Empresas na Pontifícia Universidade Católica do Rio de Janeiro PUC/Rio

E-mail: tatifacc@hotmail.com (Brasil)

\section{Henrique Bauer}

Mestrando em Administração de Empresas na Pontifícia Universidade Católica do Rio de Janeiro PUC/Rio

E-mail: bauer.rj@globo.com (Brasil)

\section{Marcio Almeida Assis}

Mestrando em Administração de Empresas na Pontifícia Universidade Católica do Rio de Janeiro PUC/Rio

E-mail: marcio.almeida.assis@gmail.com (Brasil)

\section{RESUMO}

Movimentos surgem aos milhares no ciberespaço, inclusive os movimentos de resistência a marcas e consumo. Cada vez mais a Internet se transforma em um meio onde as reclamações individuais deixam de ser um evento privado e tornam-se públicas, mobilizando outros consumidores sobre práticas e injustiças causadas pelas organizações. $O$ presente trabalho trata de uma pesquisa qualitativa que analisou os comportamentos e as razões de resistência à Globo em comunidades virtuais. Comunidades dedicadas à resistência a tal organização estão às centenas no site de relacionamento Orkut. Destas foram escolhidas e investigadas as cinco comunidades com o maior número de membro. Para cumprir tal objetivo foi escolhida a netnografia como meio de investigação do comportamento dos participantes dessas comunidades. Os pesquisadores imergiram nas comunidades, realizando observações nas mesmas, copiando dados de fóruns das comunidades virtuais pesquisadas. A partir das observações das interações nas comunidades e da análise do conteúdo, foram identificados cinco motivos para a resistência à organização e o ciberativismo.

Palavras-chave: Resistência; Ciberativismo; Comunidades virtuais. 


\section{INTRODUÇÃO}

Desde o início da década de 1980 que se percebe uma maior preocupação de pesquisadores da área de marketing em propor e desenvolver abordagens alternativas para entender melhor fenômenos do consumo através de uma perspectiva interpretativista, buscando ampliar os conceitos na área além da visão simplista de utilitário e racional (Pinto \& Santos, 2008).

Pesquisadores têm dado foco ao papel do significado social e simbólico das marcas para os consumidores. Marcas demonstram ter um papel importante na criação da identidade e os consumidores decidem se aceitam ou se rejeitam tais marcas com base no valor simbólico destas (Mühlbacher et al., 2006). Indivíduos para satisfazer os seus desejos buscam produtos menos pelo valor de uso e mais pela ligação que este faz às comunidades/tribos que esses participam (Cova, 1997).

Embora grande parte das pesquisas sobre consumidor dê ênfase no consumo de marcas pelo lado positivo, é crescente o número de trabalhos voltados à resistência ao consumo (Lee, Motion \& Conroy, 2009).

Resistir ao consumo não é postura fácil de adotar, principalmente em alguns itens que podem ser emocional e financeiramente custosos (Cherrier, 2009). As pessoas frequentemente usam marcas e produtos que comunicam certa identidade, representando sua imagem. Com novas tecnologias, tornaram-se possíveis mundos virtuais onde o consumidor pode representar a si mesmo (Schau \& Gilly, 2003).

A Internet pode ser vista como uma ferramenta de empowerment, já que fornece aos consumidores acesso a um corpo de informação e conhecimento com baixo dispêndio de pesquisa. Com tais facilidades, os consumidores passaram a exercer um maior controle sobre as suas atividades de consumo, abandonando seus papéis passivos (Harrison, Waite, \& Hunter, 2006). Os descontentes com marcas ou corporações passaram a criar comunidades, fóruns, blogs e websites no qual denunciam, queixam-se, repudiam ou protestam publicamente sobre práticas de empresas (Albuquerque, Pereira, \& Bellini, 2010).

As comunidades virtuais têm se mostrado uma fonte rica de informações, pouco explorada, na definição de segmentos de mercado e de estratégias para uma abordagem mais efetiva. Através dessas comunidades seus membros revelam suas características pessoais, psicológicas e sociais. A

REMark - Revista Brasileira de Marketing, São Paulo, v. 10, n. 3, p. 84-105, set./dez. 2011. 
participação nessas comunidades possibilita a caracterização de seus integrantes com base nos seus interesses e estilos de vida (Añaña, Vieira, Petroll, Wagner, \& Costa, 2008).

Apesar do crescimento da Internet, a televisão ainda é um dos veículos de comunicação mais influentes do mundo, atuante na política, na cultura e na sociedade em geral (Gurovitz, 2002 como citado em Oliveira, 2005). Além disso, é a fonte de informação de muitas famílias brasileiras (Tureta, Cunha, \& Rosa, 2008), e faz parte do entretenimento destas (Borelli \& Priolli, 2000 como citado em Oliveira, 2005). As telenovelas são consideradas retratos da sociedade. Por conta do seu sucesso, estas são consideradas por teóricos como alienantes e impositoras de ideologias (Castro, 2007).

Segundo Coimbra (2001), apesar do crescimento dos meios de comunicação no Brasil, ocorreu à centralização e o controle por poucos grupos. Nove grupos controlam quase $90 \%$ de toda comunicação social do país. Para Tureta et al. (2008), além da concentração, essa mídia é dominada por algumas famílias, tais como as famílias Abravanel, Marinho, Saad e Macedo.

Os objetivos do presente estudo são investigar as justificativas ou argumentos que apoiam o discurso das comunidades virtuais dedicadas à resistência à Globo. A justificativa para o estudo é que tal organização se trata da maior rede de comunicação e entretenimento do país e nos últimos anos tem sido alvo de críticas através de e-mails, blogs e comunidades virtuais, podendo-se falar em um movimento de resistência aos seus produtos.

Sobre a organização pode-se dizer que esta foi fundada em 1965, como TV Globo (Memória Globo, 2005), e atualmente conta com doze mil funcionários (diretos e indiretos) e cinco emissoras próprias e mais de cem emissoras afiliadas, com sua transmissão cobrindo 99,84\% do país. Sobre a sua audiência, pode-se dizer que alcança $74 \%$ de participação no horário nobre, $56 \%$ no matutino, $59 \%$ no vespertino e $69 \%$ no horário noturno. Vários programas produzidos pela organização, como novelas e jornalismo, já foram transmitidos em cento e trinta países de diversos continentes (Globo.com, 2010).

Para cumprir os objetivos do presente trabalho, utilizou-se a netnografia como método de investigação às comunidades virtuais. Dentre as centenas existentes no site de relacionamentos Orkut foram investigadas as cinco comunidades anti-Globo com o maior número de participantes. O trabalho apresenta uma revisão bibliográfica sobre comunidades virtuais e resistência do consumidor e ciberativismo, seguido pela metodologia e a representação dos dados encontrados na pesquisa em tais comunidades.

REMark - Revista Brasileira de Marketing, São Paulo, v. 10, n. 3, p. 84-105, set./dez. 2011. 


\section{REVISÃO BIBLIOGRÁFICA}

\subsection{COMUNIDADES VIRTUAIS}

A Internet tem facilitado às pessoas do mundo inteiro a se comunicar, encontrar pessoas e se reunirem em grupos, tendo como base uma rede ampla de interesses culturais e afiliações sociais. Tais grupos têm recebido frequentemente a denominação de comunidades virtuais ou online. $\mathrm{O}$ principal interesse dos participantes dessas comunidades virtuais é a troca de informações, e a busca por novas amizades e apoio social (Fonseca, Gonçalves, Oliveira, \& Tinoco, 2008).

Stolterman, Croon e Âgren (1997) definem comunidade virtual como um número de pessoas que se relacionam através do uso de uma tecnologia específica e afirmam que saber como as comunidades virtuais afetarão a vida e o futuro da sociedade é uma questão importante que deve ser entendida e estudada. Pois, tais comunidades impactam nas experiências de seus usuários, servindo as necessidades de comunicação, informação e entretenimento desses (Lin, 2006).

O trabalho de Valterson (1996) expõe que as comunidades virtuais são um fenômeno novo. Comunidades virtuais são definidas como um número de pessoas que se relacionam regularmente (Almeida, Mazzon, \& Dholakia, 2008). Não é necessário que essas pessoas se encontrem fora da web, e essas se relacionam pela divisão de interesses, problemas ou ideias. As primeiras comunidades virtuais surgiram no final da década de 1970 (Scaraboto, 2006). No início tais comunidades eram formadas por pesquisadores, que possuíam interesse na cooperação para pesquisas. A partir de 2002 que sites de relacionamentos em que se desenvolveram laços entre indivíduos como amigos, tais como Orkut e Facebook, surgiram (Downes, 2005).

Essas comunidades virtuais são redes de relacionamentos interativas e organizadas em torno de um interesse comum ou uma finalidade compartilhada (Abreu, Baldanza, \& Sette, 2008; Almeida et al., 2008; Hummel \& Lechner, 2002). Um elemento presente nessas comunidades é o sentimento de pertencimento. Este é visto como condição necessária para a existência da comunidade no ciberespaço, e que o estudo disso busca entender como as novas tecnologias de comunicação têm influenciado e modificado a socialização das pessoas, e novas estratégias mercadológicas nesse novo contexto. Ao analisar o Multiple Sports Networking, Blanchard e Markus (2002) identificaram que os membros dessa comunidade virtual conseguem se reconhecer,

REMark - Revista Brasileira de Marketing, São Paulo, v. 10, n. 3, p. 84-105, set./dez. 2011. 
se identificar, e possuem obrigações com a comunidade, e este último é o que os atrai para a comunidade.

Existem os prosumers, que seriam consumidores que se identificam como membro de um determinado grupo e que coletivamente divide uma cultura de consumo - incluindo construção de práticas, identidades e significados. Os prosumers são ligados à tecnologia, interagem, trocam informações, sugestões, buscam viver o momento, aproveitando no máximo o presente, e fazem uso da tecnologia para se comunicar na rede de contatos e procurar o que tem de melhor em relação aos seus interesses (Fonseca et al., 2008).

Ouwersloot e Scrhöder (2008) discorrem sobre a existência de comunidades de marca na web, que são estruturadas em relações sociais pelos admiradores da marca. O trabalho sobre a comunidade da Nutella (Cova \& Pace, 2006), por exemplo, mostrou como funcionava a comunidade que era gerenciada pela própria marca e não pelos membros.

As comunidades de marca servem para múltiplos objetivos para diferentes pessoas. Reduzir a incerteza na hora da compra, expressar o envolvimento com o tipo de produto, consumir o produto que os membros daquela comunidade consomem e dividir o valor simbólico que envolve a marca do produto (Ouwersloot \& Schröder, 2008).

Schröeder, Berger e Klering (2007) descrevem que, nas comunidades virtuais, a aproximação das pessoas acontece de diversos modos: curiosidade por um assunto em comum, pelo convite de alguém próximo, etc. Um ponto interessante revelado pelos autores é que há um certo anonimato e uma sensação de segurança em relação a outras pessoas, fazendo com que as pessoas se mostrem no ambiente virtual de um modo que dificilmente fariam em encontros reais.

Valck (2005) afirma que as comunidades virtuais têm como característica baixas barreiras de entrada e saída de um grupo. A participação em comunidades virtuais é voluntária. As pessoas participam daquelas com as quais se identificam (Scaraboto, 2006). Se um indivíduo não concorda mais com um grupo, este sai da comunidade e se junta a outro que se pareça mais com as suas características e crenças.

As comunidades virtuais têm se mostrado uma fonte rica de informações, pouco explorada, na definição de segmentos de mercado e de estratégias para uma abordagem mais efetiva. Através dessas comunidades seus membros revelam suas características pessoais, psicológicas e sociais. A participação em comunidades virtuais possibilita a caracterização de seus integrantes com base nos seus interesses e estilos de vida (Añaña et al., 2008). Em alguns casos, fornecendo informações

REMark - Revista Brasileira de Marketing, São Paulo, v. 10, n. 3, p. 84-105, set./dez. 2011. 
sobre as relações sociais dos consumidores com marcas e produtos, o comportamento dos consumidores e a relação entre si destes (Scaraboto, 2006).

Nem sempre essas comunidades são formadas para dividir um interesse positivo a uma marca. Há várias que se concentram em declarar a sua rejeição a atividades de marketing, podendo tais comunidades serem chamadas de comunidades de boicote (Scaraboto, 2006) ou resistência.

\subsection{RESISTÊNCIA DO CONSUMIDOR E COMUNIDADES ANTIMARCA}

A grande rede tem se transformado no meio onde as reclamações individuais deixam de ser um evento privado e tornam-se públicas, mobilizando outros consumidores sobre práticas e injustiças causadas pelas organizações. Isso modificou a participação social dos consumidores, sendo uma nova forma de ameaça, protesto, boicote, ativismo contra uma organização ou uma marca (Kucuk, 2008; Albuquerque et al., 2010). O boicote não é apenas uma demonstração da força coletiva dos consumidores, mas também uma expressão complexa da individualidade de cada participante (Farah \& Newman, 2010).

Os trabalhos de Barros, Sauerbronn, Darbilly e Costa (2008) e Hemetsberger (2006) revelam ser crescente o interesse pelo tema de resistência do consumidor por acadêmicos e que tal comportamento não é um fato novo. A resistência do consumidor pode não ser total, mas que pode ser entendida dentro de determinados contextos, e estes podem se apresentar sob diversas formas. Ocasionalmente o consumidor direciona a sua resistência a determinados alvos, como movimentos antiglobalização. Em muitos casos, o consumidor não deseja abandonar o consumo ou reduzir o mesmo (Lee et al., 2009).

As comunidades antimarcas consistem em um grupo de consumidores que resistem a significados e valores impostos que são descritos por uma marca (Hollenbeck \& Zinkhan, 2006). Quando estas ocorrem no ambiente virtual, podem ser definidas como reunião informal online de consumidores em que há um processo de orientação e aconselhamento anticonsumo dos seus membros. Destaca-se sobre as comunidades o ciberativismo onde um grupo de pessoas que tenta mobilizar e organizar outras para protestar ou agir com manifestações duras contra o alvo da causa defendida (Albuquerque et al., 2010).

Close e Zinkhan (2007) descrevem que a 'resistência de mercado' é vista quando o consumidor não se envolve com comportamentos comerciais estabelecidos e ritualizados. Fatores

REMark - Revista Brasileira de Marketing, São Paulo, v. 10, n. 3, p. 84-105, set./dez. 2011. 
situacionais e sócio-culturais podem facilitar ou moderar esse tipo de comportamento. Para Fournier (1998), alguns pesquisadores do tema relacionam a resistência do consumidor ao mercado como um todo, já outros relacionam a prática de marketing, ao comportamento das organizações. E como a resistência se manifesta de diversos modos, permite estudos em diversos níveis de análise.

Ritson e Dobscha (1999) classificam a atitude de resistência do consumidor em três: a rejeição em que consumidores, tanto como indivíduos quanto em grupos, reclamam junto às empresas; boicote a um produto ou empresa; ou um movimento individual ou de um grupo em que estes se engajam em comunicar a sua rejeição a uma organização.

Moisio e Askegaard (2002) acreditam que a definição de resistência do consumidor pode ser dividida em pelo menos três classes de significados. A primeira pode ser entendida como um modo de resposta racional ou emocional às condições de mercado. A segunda classe é um reflexo de uma aversão a um tipo de produto ou serviço. E a última pode ser entendida como um ato micro político, como uma retaliação a práticas ou culturas dominantes.

Kozinets e Handelman (1998) discorrem que ações de resistência do consumidor podem ganhar diversas formas, com manifestações individuais ou coletivas. Neste trabalho, os autores descobriram que alguns consumidores viam o boicote a produto/marca como um veículo de auto expressão, vendo a si mesmas como pessoas diferentes que acordaram, cresceram ou passaram a ter controle de si, negando qualquer envolvimento com uma marca que possua um comportamento que para eles não é ético. Os autores perceberam através das entrevistas que a discrepância entre os valores do consumidor e das organizações faz com que aquele boicote estas.

Cova e Dalli (2009) corroboram com a visão apresentada no trabalho de Kozinets e Handelman (1998) e descrevem que consumidores que resistem a marcas reconhecem e são contrários à manipulação, e buscam o seu jeito de satisfazerem suas necessidades, evitando o que o mercado e seus agentes tentam impor.

No grupo pesquisado por Cherrier (2009) foram identificados dois tipos de identidade de consumidores resistentes: a heróica e a calculista. A primeira está voltada a resistir ao sistema de dominação, tentando mostrar valores que seriam uma alternativa à sociedade. A última identidade tenta desenvolver um ambiente percebido como mais autêntico ou mais pessoal, onde desejos de inclusão ou exclusão não são determinados pela cultura.

Iyer e Muncy (2009) classificaram as pessoas com práticas anti-consumo em quatro tipos. Primeiro, os que tentam reduzir em benefício da sociedade e do planeta, pensando no impacto global que o consumo provoca. Segundo, as pessoas com estilo de consumo mais simples. Terceiro,

REMark - Revista Brasileira de Marketing, São Paulo, v. 10, n. 3, p. 84-105, set./dez. 2011. 
os ativistas de mercado que rejeitam marcas ou produtos específicos por acreditarem que estes ou as organizações que o produzem prejudicam o meio ambiente ou tem práticas anti-éticas. E por último, os que apresentam um comportamento oposto ao de lealdade a marca, comportamento frequentemente associado a uma experiência negativa com uma marca ou um produto.

Piacentini e Banister (2009) classificam em três categorias a rejeição a marcas. Na primeira, os consumidores rejeitam uma marca por conta de uma experiência negativa com esta. Na segunda, os consumidores renegam o consumo por não verem a marca como parte da sua identidade. $\mathrm{Na}$ última, os consumidores questionam as forças dominantes ou normas de consumo enraizadas.

\section{METODOLOGIA}

Este artigo trata de uma pesquisa qualitativa que pretende analisar as razões e os comportamentos de resistência à Globo em comunidades virtuais. Comunidades dedicadas à resistência a tal organização estão às centenas no site de relacionamento Orkut. Destas foram escolhidas e investigadas as cinco que possuem o maior número de membros. As comunidades são Eu odeio a Rede Globo, O Brasil diz não à Rede Globo, Eu não assisto à Globo, Eu odeio a rede Globo de TV, Rede Globo: manipuladora.

Para cumprir tal objetivo foi escolhida a netnografia, conforme as recomendações de Kozinets e Handelman (1998) como meio de investigação do comportamento dos participantes dessas comunidades, por ser considerado um bom método para observação e contato das comunidades antimarca. Os pesquisadores imergiram nas comunidades, realizando observações nas mesmas entre março e junho do presente ano. Como destacado por Kozinets (2002 como citado em Almeida, Mazzon \& Dholakia, 2008) ao discorrer sobre netnografia, dados foram copiados de fóruns das comunidades virtuais pesquisadas, e observações das interações nestas.

Vale destacar que o trabalho utilizou a observação participante, descrita como a participação mais íntima possível do pesquisador às atividades, à vida do grupo estudado, e aos processos que definem seus interesses e afetos (Ladeira, 2007; Malhotra, 2005). A intenção dessa participação é oferecer um ponto de vista do que ocorre com o grupo, de como este é, de dentro, com o pesquisador como integrante do grupo (Genzuk, 2003).

Para o tratamento dos dados copiados nos fóruns das comunidades fez-se uso da análise de conteúdo que, segundo Godoy (1995, p. 23): “parte do pressuposto de que, por trás do discurso

REMark - Revista Brasileira de Marketing, São Paulo, v. 10, n. 3, p. 84-105, set./dez. 2011. 
aparente, simbólico e polissêmico, esconde-se um sentido que convém desvendar”. "A análise de conteúdo aparece como uma ferramenta para a compreensão da construção de significado que os atores sociais exteriorizam no discurso" (Silva, Gobbi, \& Simão, 2005, p. 74).

A pesquisa seguiu a abordagem interpretativa. As categorias que se apresentam na representação dos resultados surgiram naturalmente ao longo da análise dos depoimentos coletados nas comunidades virtuais.

As limitações do trabalho se dão pelo próprio método escolhido, pois possui um foco restrito em comunidades virtuais, com a ausência de dados confiáveis que possam identificar os informantes, e a necessidade do pesquisador ter uma boa habilidade de interpretação. A netnografia utiliza apenas textos, então não há como estabelecer uma comparação entre

\section{REPRESENTAÇÃO DOS RESULTADOS}

No discurso dos membros das comunidades estudadas foram encontradas as razões para a resistência e o ciberativismo nas comunidades. A partir destes, aqui analisados como duas categorias, foram identificados a programação da emissora, a defesa a outros canais, o possível preconceito a grupos religiosos, a possível manipulação da informação pela organização, a rejeição à televisão como meio de informação como razões para a resistência. E as agressões verbais incentivadas, o boicote à organização, a invasão e troca de ofensas entre prós e contra Rede Globo, e a comemoração dos baixos índices de audiência como indícios do ciberativismo nas comunidades. Os membros das comunidades não tiveram os seus nomes revelados.

\subsection{AS RAZÕES PARA A RESISTÊNCIA}

\subsubsection{A PROGRAMAÇÃO DA EMISSORA}

Um dos pontos que aparecem com frequência no discurso dos membros das comunidades era como estes veem a imagem que a emissora passa em seus programas. Alguns citam a imagem que esta transmite sobre o Brasil, outros de que os programas exibidos por esta influenciam a discórdia dentro das famílias e alienam os seus telespectadores. Outros ainda discorrem sobre o fato

REMark - Revista Brasileira de Marketing, São Paulo, v. 10, n. 3, p. 84-105, set./dez. 2011. 
da organização ter sua sede de produção no Rio de Janeiro, e que isso influencia a qualidade dos programas.

"PASSA FORA SISTEMA GLOBO COM SUAS NOVELAS E SEU BBB (BIG BURROS BRASILEIROS). ALIÁS, PRA QUE SERVE NOVELAS, SENÃO PRA ALIENAR, ESTIMULAR A VIOLENCIA E OUTROS ABSURDOS".

"muitos filmes ficam horriveis quando a dublagem possui sotaque carioca. reparem q a essência da globo está nas novelas, programas humorísticos, bbb, e outras m... que vem do RJ. a globo é subdividida em Globo (tradicional do Rio) e Globo de São Paulo. reparem que os programas da globo de SP são menos piores (Jornal Hoje, Altas Horas, Profissão Repórter, Fórmula 1, Auto Esporte, etc..), e os do Rio (novelas, fantástico, casseta e planeta, mais você, tv xuxa, vídeo show, zorra total, tv globinho). está claro que a globo é uma porcaria"

Filmes repetidos foram citados diversas vezes como um dos motivos de resistência à emissora. Nomes de filmes mais reprisados pela emissora tornaram-se razões de sarcasmo pelos membros das comunidades.

"dificil listar um no pacote de 10 que (não) se revesa nos últimos 20 anos na sessão da tarde"

“impacto profundo ... que já não causa + impacto nenhum, de tanto que já foi reprisado !!!!”

“os filmes da Barbie ... são tããããããão legais..."

Em muitas postagens, os participantes das comunidades discorrem sobre a sua indignação, revolta com os programas que não mudam, que na opinião da maioria são ruins e/ou ultrapassados.

"Odeio a Globo porque a sua Programação é um s... Se você perceber a programação dela é a mesma há séculos. Sempre passou Faustão, sempre passou vídeos que não tem nada de show, aquelas novelas horríveis e entre outras babaquices que eles insistem em passar. Nunca colocam uma coisa nova, um programa novo é sempre a mesma babaquice. Eu tô fora da globo"

"a globo insiste muito em programas nada a ver. por ex. a zorra total não tem humorista de verdade, eles forçam as coisas.um bom humor tem que ser natural. a grande família dá de $10 \times 0$ nesses programas nada a ver. casseta e planeta é outra m..., programa do didi não presta. o faustão é meia boca.malhação não existe, sem comentários. deviam de passar menos novelas e passar mais programas igual o do caldeirão do Huck.onde envolve mais o povo."

Nem sempre o ódio ou a resistência à organização se traduz no se recusar a assistir aos programas por esta produzidos. Muitos membros demonstram que assistem, ou assistiram, aos programas e até mesmo opinam sobre a qualidade desses.

"Infelizmente, é a melhor emissora de tv aberta do país! Isso é fato!!! Mas o pacote de manipulações é o que incomoda, e muito! Fico muito triste quando tento (em vão) escolher uma

REMark - Revista Brasileira de Marketing, São Paulo, v. 10, n. 3, p. 84-105, set./dez. 2011. 
outra melhor, na tv aberta, e não consigo! Tanto é que minha crítica não é somente para a Globo, mas sim para todas as redes, que tentam, tentam, tentam... mas não conseguem ser melhores do que a "Gorda Platinada"... Pobre de nós, telespectadores!"

"Todos são terriveis: novelas, séries, filmes, programas de humor, programas infantis, jornais, "revistas semanais televisivas"... os três que ficam acima da média (b...), aliás bem acima da média, são o Profissão Repórter, o Jornal da Globo (meia-noite) e o Programa do Jô. Reparem que todos os melhorzinhos costumam passar só depois das 23:00 h, acho que esse é o modo da Globo poder afirmar que tem programas bons. No entanto ela faz questão de que isso não fique disponível para o Grande Público. Preferindo deixar suas novelas "das oito" a cargo disso."

\subsubsection{DEFESA A OUTRO CANAL}

Nos tópicos das comunidades pôde ser visto com frequência os participantes defendo outro canal, no caso a Record, fazendo comparações entre as duas.

"Novelas da RECORD são melhores do que as da Globo? Com certeza até as histórias e os roteiros tem mais vida e menos sexo..."

"A Record pelo menos tenta, inventa, cria programas novos e a Globo todo ano a mesma programação, nada muda ali. Assisto a todos os canais, mas sinceramente a Record tá se saindo bem, programas $p /$ todos os gostos!"

Muitos participantes de tais comunidades rebatem as discussões sobre as emissoras, rejeitando a ideia de se fazer apologia a outra.

"Não entendo vocês falam mal de uma emissora, mas fazem propaganda de outra (...) essas emissoras brasileiras fora a cultura, é tudo farinha do mesmo saco!!"

"Globo x Record. Isso ai é briguinha pra dar ibope... idiotas são aqueles que compram essa briga"

\subsubsection{PRECONCEITO A GRUPOS RELIGIOSOS}

Embora muitos membros descrevam que a emissora apresenta preconceito contra grupos religiosos, nota-se nos depoimentos dos membros das comunidades que esse preconceito seria destinado apenas aos evangélicos.

REMark - Revista Brasileira de Marketing, São Paulo, v. 10, n. 3, p. 84-105, set./dez. 2011. 
“A globo não mostra! Quando há eventos evangélicos a globo não mostra e faz cobertura desses eventos, ainda fala que eles atrapalham o trânsito. Será que ninguém percebe isso? Os jornais têm que informar a notícia e não incitar o ódio."

"É só ver que nunca falaram bem dos evangélicos nas novelas. Dos personagens evangélicos em novelas e minisséries da globo, um era um pastor corrupto (pegaram um ator com a cara do Edir Macedo pra variar), mais recentemente em América tinha uma crente safada e por aí vai. Qdo há personagem evangélico em uma novela da globo pode ter certeza que é pra denegrir a imagem dos evangélicos".

\subsubsection{A POSSÍVEL MANIPULAÇÃO DA INFORMAÇÃO PELA ORGANIZAÇÃO}

Dentre os motivos mais citados para a resistência à Globo, a possível manipulação da informação é o que tem mais discussões. Os depoimentos apresentados abaixo demonstram bem o sentimento dos membros das comunidades sobre o assunto. Os depoimentos discorrem tanto sobre a forma de divulgação da informação quanto aos programas que a organização transmite.

“Como já diz 'Gabriel o pensador' na música 'até quando'... 'a programação existe pra manter você na frente, na frente da TV, que é pra você não ver que o programado é você!' Globo, formadora de opinião, manipuladora, e como já diz uma pichação secular que tem na AV. Brasil no RJ, 'Rede Globo, câncer da nação!'”

"Eu ainda não acredito que exista alguém que acredita nas coisas que veem nessa p... de emissora. É tudo manipulado, sabotado, boicotado, distorcido. Eu odeio os apresentadores desta m..., odeio os programas mentirosos"

“ACHA QUE É DONA DO BRASIL: SUAS REPORTAGENS SÃO TODAS VOLTADAS PARA COMPORTAMENTO, ACHA QUE TEMOS QUE NOS COMPORTAR COMO ELA QUER...ISSO É DITADURA!"

\subsubsection{REJEIÇÃO À TELEVISÃO COMO MEIO DE INFORMAÇÃO}

Alguns membros da comunidade incentivam outros membros a abandonar a televisão como meio de entretenimento e informação. Afirmam que o problema não seria a emissora, mas a mídia e divulgam outros meios dos participantes se entreterem e buscarem informações.

REMark - Revista Brasileira de Marketing, São Paulo, v. 10, n. 3, p. 84-105, set./dez. 2011. 
"eu estou há 10 anos sem ver a globo ou qualquer outro canal só uso a tv para ligar meu Xbox 360 nem antena tem e só para filmes e jogos eu baixo tudo na internet uahuauahau”

"eu nao vejo $T V$. aqui na net temos canais online q passam filme, documentários, desenhos e vc escolhe o q ve quer ver... pra que televisão? Hahaha só vai servir pra ver esportes ao vivo mesmo"

"a questão não é a globo, é a mídia de forma geral, que manipula informações e tem poder de alienar pessoas, vcs podem assistir, ler e escutar qualquer coisa, porém que não seja de forma inocente...."

Em algumas postagens, quando algum membro afirmava o abandono à Globo, isto é, não assistia aos seus programas, enquanto alguns parabenizavam o membro da comunidade, outros opinavam, em muitos casos de modo agressivo, de que aqueles deveriam abandonar não apenas à emissora, mas também a televisão.

"parabéns, mas procure ser mais seletivo com relação ao que vai assistir nas outras emissoras, a record por exemplo tá tão ruim qto a globo."

"Não creio que isso seja algo para se (van)gloriar, é preciso conhecer para opinar. Como já foi dito a questão não é assistir, e sim se conformar com tamanha alienação."

Parabéns o c..., agora falta Record, SBT, rede tv...depois que parar de se deixar alienar e se curvar perante a estas máfias, será digno de Parabéns.

\subsection{O CIBERATIVISMO}

\subsubsection{AS AGRESSÕES VERBAIS INCENTIVADAS}

Nas comunidades investigadas foram encontrados tópicos em que os participantes dessas divulgavam a sua indignação com a organização, utilizando palavras de baixo calão. Tal comportamento representa uma forma de retaliação, manifestando-se através de ofensas escritas (Albuquerque, 2010). Repetidas vezes os participantes incentivavam outros participantes a protestarem contra a Rede Globo. Alguns utilizaram o sarcasmo para demonstrar a sua opinião contra a emissora.

“esse tópico é pra todos possam extravasar, colocar pra fora todo o ódio, nojo e repúdio a essa emissora nojenta... e eu começo: Hey, globo ..., SUA EMISSORA NOJENTA, COMANDADA POR UM BANDO DE FILHOS DA P... E QUE QUEREM MANIPULAR O POVO COM UMA

REMark - Revista Brasileira de Marketing, São Paulo, v. 10, n. 3, p. 84-105, set./dez. 2011. 
PROGRAMAÇAO ALIENANTE SUJA, ... TAMBÉM TODO AQUELE QUE DEFENDE ESSA M....VAMOS LÁ GALERA! NAO DEIXEM DE POSTAR SUAS OPINIÕES...."

"EU ODEIO A REDE GLOBO. Essa emissora podre que só quer que o Brasil se f.... ABAIXO A REDE GLOBO."

"f...-se a globo... ai que gostoso poder expressar o nojo que tenho dessa emissora..."

“BRASILEIROS VAMOS DAR O FIM NESSA M... QUE É A GLOBO...NÓS NÃO SOMOS BURROS! MUDA BRASIL!"

\subsubsection{O BOICOTE À ORGANIZAÇÃO}

Albuquerque et al. (2010) discorrem que consumidores podem recusar-se a consumir determinada marca como uma forma de boicote. Este pode ser uma ação planejada e coletiva com a intenção de prejudicar a imagem de uma marca ou organização, diminuindo assim a possibilidade de compra do produto ou serviço desta.

Pôde ser visto que em algumas comunidades existiam postagens sobre criar um dia em que os participantes das comunidades não assistiriam à Rede Globo, com a intenção de reduzir drasticamente a audiência da emissora como uma forma de protesto. Em uma das postagens, um dos dias citados seria primeiro dia de julho deste ano.

\section{“Um dia sem Rede Globo}

E ae pessoal, vamos marcar um dia onde todos nós dessa comu, e outras que Odeiam a m... da Globo??? E quem sabe noticiar na tv que no dia "tal" a rede globo teve baixos índices de audiência... Ia ser $d+$ né? Que tal?

Que tal no dia $1^{\circ}$ de Julho?"

Durante a Copa do Mundo, houve um episódio de desentendimento entre um repórter da emissora e o técnico da seleção brasileira de futebol. A partir de tal episódio surgiram campanhas diversos sites da Internet, inclusive nas comunidades virtuais investigadas. Os depoimentos abaixo ilustram algumas postagens sobre a campanha nas comunidades virtuais e como diversos membros das comunidades incentivavam outros a participar da campanha e entender o que era a mesma.

"1 DIA SEM GLOBO $>$ SEXTA NÃO ASSISTA O JOGO NA GLOBO PARTICIPE. NA SEXTA ASSISTA BRASIL VS PORTUGAL NA BAND OU EM OUTRA

REMark - Revista Brasileira de Marketing, São Paulo, v. 10, n. 3, p. 84-105, set./dez. 2011. 
EMISSORA QUE NÃO SEJA AFILIADA DA REDE GLOBO...QUE A GLOBO RESPEITE O TRABALHO DOS OUTROS, SÓ PQ NÃO DEU MORAL PRA PODEROSA.A MESMA ATÉ PEDIU A FIFA PARA SUSPENDER O DUNGA.. ISSO É COISA DE QUEM NÃO GOSTA DO BRASIL E SIM DO PODER... SEXTA FEIRA DIGA NÃO A REDE GLOBO...”

"Vamos deixar a Globo sentir a força dos brasileiros unidos! \#diasemglobo! Sexta, ninguém assiste o jogo na Globo!"

"Pela primeira vez vi muita gente contra a Globo..... a notícia sobre o Dunga e o "peitaço" que ele deu no sistema ditatorial da mídia brasileira tinha mais de 12 mil mensagens contra a globo...e a campanha lá era Globo = Ibope Zero na sexta feira....vamos divulgar e mostrar que essa m... já cansou todo mundo..."

Alguns membros das comunidades utilizaram o cinismo, que pode ser entendido como uma forma do consumidor repudiar, rebaixar a organização ou marca de forma irônica ou sarcástica (Albuquerque et al., 2010), para incentivar a campanha de boicote à organização.

"A vingança é sua, a vingança é nossa, é de quem quiser, quem vier! Nosso sonho de liberdade já começou! \#DiaSemGlobo”"

"DUNGA... meu Herói. Chutou o pau da barraca da Globo. Dunga Schuazeneger...meu herói.Chumbo neles Dunga.”

Outros participantes das comunidades incentivam o boicote à organização em outros dias do ano e até mesmo pedem para que uma nova campanha seja criada, onde os participantes abandonariam a organização, não assistindo a nenhum programa seu.

"não vamos ver a copa na globo (e aturar além de tudo o insuportável do Galvão Bueno)... qualquer emissora, menos a globo. Depois poderemos nos unir para marcar um outro dia, e o motivo do posterior boicote. Todos nós devemos combinar dia e horário, para que a globo SINTA a queda de audiência, e o boicote se torne público na internet."

"um dia não, uma vida sem Globo."

"Eu já não assisto a globosta há um tempão, nada é educativo e não tira nenhum proveito assistindo as porcarias que passam neste canal. APOIO "A VIDA" SEM GLOBO, UM DIA É MUITO POUCO”

\subsubsection{CHUMBO TROCADO DÓI...}

Em quase todas as comunidades pesquisadas foram encontrados postagens em que pessoas defendem a Globo, atacando, e até mesmo ofendendo verbalmente, os membros das comunidades anti-Globo.

REMark - Revista Brasileira de Marketing, São Paulo, v. 10, n. 3, p. 84-105, set./dez. 2011. 
"A rede Globo é a melhor... do mundo. Vocês não reconhecem uma potência mundial"

\section{"Globo Orgulho Nacional}

Vocês que dizem que a globo não presta pq vcs têm aquelas anteninhas com bombril q $n$ dá pra assistir direito. eu que tenho TV a cabo sei que a globo é o melhor canal que existe, ralé gosta mesmo é da redetv pra assistir fofoca da Sônia Abrão ... O Brasil deve muito a globo, ela representa nosso país no exterior. Globo = ORGULHO NACIONAL",

"bando de invejosos. essa comunidade parece só ter gente invejosa, a globo tem essa credibilidade pq ela teve seus méritos, essa comunidade deveria chamar comunidade dos fracassados sem potencial"

Porém, tais ataques têm provocado a manifestação dentro das comunidades anti-Globo para que seus membros também ataquem as comunidades pró Rede Globo. Os membros das comunidades mostram os ataques sofridos e propõem uma "reação".

\section{“O Dia 'D' - A invasão dos fakes}

Bom... a pedidos e depois de terem desviado a atenção para assuntos pessoas de outro tópico, resolvi criar esse tópico para propor o seguinte: depois da polêmica dos fakes da REDE GLOBO DE TELEVISÃO (que particularmente está me enchendo o s..., mandando scraps toda hora e postando em minhas comunidades), pensei em combinarmos um dia para invadir a comunidade da Globo (utilizando perfis fakes), divulgando diversas comunidades anti-globo, disponibilizando matérias, documentários, etc. Pensei no dia $1^{o}$ de Julho (não tem nada específico a ver com essa data, apenas está próximo e dá tempo da gente se organizar). Eu já tenho um perfil fake, mas estou esperando a galera se mobilizar. Aguardo a resposta $e$ compreensão de todos e sugestões e criticas sempre são bem vindas (quanto tem argumentos, claro)"

"Como vocês vêm notando, que sempre tem um Global invadindo a nossa comunidade? E não é só essa não, várias comunidades Anti-Globo sempre têm um Global dizendo que a gente tem inveja, que somos favelados, que somos isso e aquilo, e eles sempre botam a Globo lá em cima. O meu objetivo é, organizar aqui nesse tópico, uma Rebelião Anti-Globo em todas as Comunidades relacionadas a Programas, Novelas, Séries da Globo que vocês possam encontrar. Fazer uma bagunça total, já que eles fazem isso com a gente, vamos fazer pior, vamos pagar com a mesma moeda"

\subsubsection{DIVULGAÇÃO E COMEMORAÇÃO PELA QUEDA NA AUDIÊNCIA}

Após o evento Dia sem Globo ocorrido por conta do desentendimento entre Dunga, técnico da seleção durante a Copa do Mundo de futebol, e repórteres da emissora, muitos membros 
divulgaram os resultados do Dia do Boicote à Rede Globo. Mesmo as notícias não indicando uma boa adesão ao movimento, os membros julgaram o evento positivo.

"IBOPE Globo desce e Band sobe...

Brasil x Corea Norte........10 pts.....16\%. Brasil x Costa do Marfim...10 pts....17,2\%. tudo indica Brasil $x$ Portugal......+13 pts. Cada ponto no Ibope é equivalente a 58.300 domicílios sintonizados. LOGO: 3x 58300 Tvs aderiram.>174 900 tvs. um inicio bem Promissor."

"Segundo a EXAME, nem arranhou... mas, não é bem assim A campanha que convocou internautas a evitar a assistir à partida entre Brasil e Portugal pela Rede Globo nesta sexta-feira (25) não parece ter surtido muito efeito. Dados preliminares apontam que a emissora registrou 44 pontos de audiência durante o jogo na Grande São Paulo, e 46 no Rio de Janeiro. Ainda assim, por conta da campanha ou não, a Band, única outra emissora aberta a transmitir os jogos no Brasil, teve hoje seu melhor índice de audiência em jogos do Brasil desta Copa do Mundo, chegando aos 13 pontos em São Paulo. Na mesma região, no confronto contra a Coreia do Norte, o canal havia ficado com 10,08 pontos, e no jogo contra a Costa do Marfim, 9,98. Os índices medidos no Rio de Janeiro mantiveram a mesma média dos últimos jogos na Band - foram 8 pontos hoje contra 7,87 no domingo e 7,97 no dia 15.Comentário: É óbvio que o aumento da audiência da BAND teve a ver com a campanha, ou seja, a audiência poderia ser melhor, então conseguimos tirar audiência da Globo e ainda tornar pública que existem pessoas que não se permitem ser manipulados pela Globo.

Fonte: http://portalexame.abril.com.br/tecnologia/noticias/dia-globo-emissora-mantemaudiencia-573392.html"

Com a discussão sobre a queda da audiência entre a Rede Globo e a ascensão da audiência de outro canal, os membros das comunidades divulgam e comemoram quando a Rede Globo registra baixos índices de audiência. Os membros divulgam informações com a fonte para reforçar o depoimento dado.

"Do outro lado do ringue...

'Com investimentos na casa dos $R \$ 300$ milhões por ano (desde 2004)..., a Record ... teve o maior "boom" de audiência de todos os tempos: 112\% na Grande SP e 127\% na audiência brasileira. O maior crescimento da rede ligada ao bispo Edir Macedo ocorreu ainda no horário mais rentável da TV, o nobre (mais de 160\%), graças às novelas. No entanto, a Record ainda tem apenas $50 \%$ da média da líder na Grande SP (9 x 18 pontos). E na média nacional a distância é ainda maior: 7,5 x 19,5 pontos. Mas as curvas estatísticas desde 2004 apontam que, enquanto a Record vem subindo de forma constante, a Globo cai. Com isso, a Record ultrapassou a então histórica vice-liderança do SBT, que agora se tornou a $3^{a}$ rede do país: de 8 pontos de média obtidos na primeira metade de 2004 a TV de Silvio Santos caiu para 6,1 pontos em 2008: queda de 24\%, ou quase um em cada 4 telespectadores.' HAHAHAHAHA!! E eu ajudo a jogar mais terra por cima..."

REMark - Revista Brasileira de Marketing, São Paulo, v. 10, n. 3, p. 84-105, set./dez. 2011. 
"record com triplo de audiência que a rede globo

A participação do humorista Carlinhos Silva, no programa "Hoje em Dia" desta quinta-feira (20), deixou a Record por vários minutos com o triplo da audiência da segunda colocada no horário, a Globo. A informação é da coluna "Ooops!", do UOL. De acordo com informações da coluna, por volta das $10 \mathrm{~h}$ a Record liderava com 15 pontos no ibope, enquanto a Globo marcava cinco pontos no horário em que exibia trechos do "Mais Você" e da "TV Globinho". "Os números são referentes à medição em tempo real, ainda não consolidada."

\section{CONCLUSÕES}

A Internet deu poder ao consumidor, onde este passou a ter um papel mais ativo com controle sobre o seu próprio consumo. Blogs, sites, comunidades virtuais passaram a representar tanto o culto a uma marca quanto o ódio a mesma.

O presente trabalho teve por objetivo analisar os comportamentos e as razões de resistência à Rede Globo em comunidades virtuais. Acredita-se que como contribuições trazidas pelo estudo estão os indícios do ciberativismo encontrados nas comunidades, onde há o incentivo ao boicote, aos ataques tanto verbais dentro da própria comunidade (expressando a raiva de muitos membros à Rede Globo) e a divulgação (e comemoração) dos membros pela redução dos índices de audiência da emissora.

Parte dos membros das comunidades comporta-se como citado pelos trabalhos de Kozinets e Handelman (1998) e Cova e Dali (2009), onde se reconhece como contrária à possível manipulação da informação pela emissora. Tais membros satisfazem as suas necessidades de assistir a programas, filmes ou documentários utilizando a Internet para obter tal material. Outro ponto a se destacar que para alguns o problema não é apenas a emissora, mas o meio de comunicação que seria tendencioso, indicando a Internet como um meio de informação e entretenimento democrático em que as pessoas podem escolher ao que assistir. Para esses membros, a televisão teria serventia apenas em jogos esportivos transmitidos ao vivo.

Embora existam movimentos de boicote nas comunidades virtuais estudadas, nem sempre a resistência à Rede Globo representa o abandono desta pelos consumidores. Muitos indicaram que ainda assistem a programação da emissora, até citando suas preferências.

Quando se trata do ciberativismo, pôde ser visto que os membros incentivam a agressão verbal de outros membros e o boicote como meio de protesto à organização e às atitudes desta. A divulgação do boicote a pessoas que estão fora dessas comunidades também é incentivada, citando

REMark - Revista Brasileira de Marketing, São Paulo, v. 10, n. 3, p. 84-105, set./dez. 2011. 
outros sites para a divulgação de campanhas contra a organização, além das propostas de contra ataque às invasões de depoimentos a favor da Rede Globo, com a mesma moeda (no caso, os membros das comunidades anti-Globo entram nas comunidades pró-Globo e criam fóruns criticando ou ofendendo a Rede Globo).

A resistência e o ciberativismo dentro das comunidades poderiam se enquadrar na terceira classe de resistência do consumidor, descrito por Moisio e Askegaard (2002), onde a resistência dos membros parece um ato micro político, uma retaliação a cultura dominante. Destacando-se a divulgação e a comemoração pela queda de audiência em alguns programas da emissora e no dia de boicote (durante a copa do mundo de futebol) como indícios disso.

Vale destacar que apesar da literatura sobre resistência do consumidor ser crescente, falando-se em características do consumidor (como ser simplista, ecologicamente correto) ou a falta de ética como causas para a resistência, não foram encontrados trabalhos que indicassem a rejeição aos meios de informação tradicionais. Pesquisas mais profundas sobre o tema, tornam-se cada vez mais relevantes, dado o crescimento do ciberativismo. Além disso, a Rede Globo torna o estudo interessante por ser a maior emissora do país.

Com base no que foi encontrado nesta pesquisa e nas limitações da mesma, têm-se como sugestões para pesquisas futuras: ampliar a investigação sobre as razões de resistência à Rede Globo com a realização de entrevistas em profundidade com os criadores e os membros mais participativos das comunidades, e investigar a resistência do consumidor aos meios de informação tradicionais (televisão, rádio e outros), se esta resistência existe.

\section{REFERÊNCIAS}

Abreu, N. R., Baldanza, R. F., \& Sette, R. S. (2008, Set-Dez). Comunidades virtuais como ambiente potencializador de estratégias mercadológicas: lócus de informações e troca de experiências vivenciadas. Perspectivas em Ciências de Informação, 13(3), 116-136.

Albuquerque, F. M. F., Pereira, R. C. F., \& Bellini, C. G. P. (2010). Do repertório de comportamentos anticonsumo: retaliação e vingança no ciberespaço. In IV ENCONTRO DE MARKETING DA ANPAD (EMA), Florianópolis. Anais ... Florianópolis: Anpad.

Almeida, S. O., Mazzon, J. A., \& Dholakia, U. (2008). Os efeitos da participação nas comunidades de marca virtuais no comportamento do consumidor: um estudo comparativo entre

REMark - Revista Brasileira de Marketing, São Paulo, v. 10, n. 3, p. 84-105, set./dez. 2011. 
comunidades gerenciadas pelas organizações e pelos consumidores. In III Encontro de Marketing da Anpad (EMA), Curitiba. Anais... Curitiba: Anpad.

Añaña, E. S., Vieira, L. M. M., Petroll, M. M., Wagner, R. P., \& Costa, R. S. (2008). As comunidades virtuais e a segmentação de mercado: uma abordagem exploratória, utilizando redes neurais e dados da comunidade virtual Orkut. Revista de Administração Contemporânea, Ed. Especial, 41-63.

Barros, D. F., Sauerbronn, J. F. R., Darbilly, L. V. C., \& Costa, A. M. (2008). Pirataria, não! Resistência. Um estudo sobre as práticas de resistência do consumidor brasileiro de música digital. In: XXXI Encontro Nacional da Associação Nacional de Pós-Graduação e Pesquisa em Administração (ENANPAD), Rio de Janeiro. Anais ... Rio de Janeiro: Anpad.

Blanchard, A. L., \& Markus, M. L. (2002). Sense of virtual community - maintaining the experience of belonging. $35^{\text {th }}$ Annual Hawaii International Conference on System Sciences.

Castro, B. C. (2007, jan-jun). Representação, imposição e negociação: a sociedade brasileira nas minisséries da Globo. Contemporânea, 5(1), (8a ed.), 66-77.

Cherrier, H. (2009). Anti-consumption discourses and consumer-resistant identities. Journal of Business Research, 62(2), 181-190.

Close, A. G., \& Zinkhan, G. M. (2007). Consumer experiences and market resistance: an extension of resistance theories. Advances in Consumer Research, 34, 256-262.

Coimbra, C. M. B. (2001, Jan-Abr) Mídia e produção de modos de existência. Psicologia: teoria e prática, 17(1), 1-4.

Cova, B. (1997). Community and consumption: towards a definition of the "linking value" of products and services. European Journal of Marketing, 31(3 / 4), 297-316.

Cova, B., \& Pace, S. (2006). Brand community of convenience products: new forms of customer empowerment - the case "my Nutella The Community". European Journal of Marketing, 40(9/10), 1087-1105.

Cova, B., \& Dalli, D. (2009). Working consumers: the next step in marketing theory? Marketing Theory, 9(3), 315-339.

Downes, S. (2005). Semantic networks and social networks. The learning organization, 12(5), 411417.

Farah, M. F., \& Newman, A. J. (2010). Exploring consumer boycott intelligence using a sociocognitive approach. Journal of Business Research, 63(4), 347-355.

Fonseca, M. J., Gonçalves, M. A., Oliveira, M. O. R., \& Tinoco, M. A. C. (2008, Dezembro). Tendências sobre as comunidades virtuais da perspectiva dos prosumers. RAE electron., São Paulo, 7(2).

Fournier, S. (1998). Consumer resistance: societal motivations, consumer manifestations, and implications in the marketing domain. Advances in Consumer Research, 25, 88-90.

REMark - Revista Brasileira de Marketing, São Paulo, v. 10, n. 3, p. 84-105, set./dez. 2011. 
Genzuk, M. (2003) A synthesis of ethnographic research. Occasional Papers Series. Center for Multilingual, Multicultural Research (Eds.). Center for Multilingual, Multicultural Research, Rossier School of Education, University of Southern California. Los Angeles. Recuperado em 16 agosto, 2009, de: http://www-rcf.usc.edu/ genzuk/Ethnographic_Research.pdf

Globo.com. (2010). História da empresa. Recuperado em 20 junho, 2010, de: http://redeglobo3.globo.com/institucional/

Godoy, A. (1995, mai-jun). Pesquisa qualitativa: tipos fundamentais. Revista de Administração de Empresas, 35(3), p. 20-29.

Harrison, T., Waite, K., \& Hunter, G. L. (2006). The Internet, information and empowerment. European Journal of Marketing, 40(9/10), 972-993.

Hemetsberger, A. (2006). When David becomes Goliath: ideological discourse in new online consumer movements. Advances in Consumer Research, 33, 494-500.

Hollenbeck, C. R., \& Zinkhan, G. M. (2006). Consumer activism on the Internet: the role of antibrands communities. Advances in Consumer Research, 33, 479-485.

Hummel, J., \& Lechner, U. (2002). Social profiles in virtual communities. Proceedings of $35^{\text {th }}$ Hawaii International Conference on System Sciences.

Iyer, R., \& Muncy, J. A. (2009). Purpose and object of Anti-consumption. Journal of Business Research, 62(2), 160-168.

Kozinets, R. V., \& Handelman, J. (1998). Ensouling consumption: a netnographic exploration of the meaning of boycotting behavior. Advances in Consumer Research, 25, 475-480.

Kucuk, S. U. (2008, Jan) Negative Double Jeopardy: the role of anti-brand sites on the Internet. Brand Management, 15(3), 209-222.

Ladeira, W. T. (2007, Jan-Jun). Teorias e métodos de pesquisa qualitativa em sociolingüística interacional. Revista de C. Humanas, 7(1), 43-56.

Lee, M. S. W., Motion, J., \& Conroy, D. (2009). Anti-consumption and brand avoidance. Journal of Business Research, 62, 169-180.

Lin, H. F. (2006). Understanding behavioral intention to participate in virtual communities. CyberPsychology \& Behavior, 9(5), 540-547.

Malhotra, N. K. (2005). Introdução à Pesquisa de Marketing. São Paulo: Pearson Prentice Hall.

Memória Globo. (2005). Jornal Nacional: a notícia faz história. (12a ed.). Rio de Janeiro: Jorge Zahar Ed.

Moisio, R. J., \& Askegaard, S. (2002). "Fighting culture" - Mobile phone consumption practices as means of consumer resistance. Asia Pacific Advances in Consumer Research, 5, 24-29.

REMark - Revista Brasileira de Marketing, São Paulo, v. 10, n. 3, p. 84-105, set./dez. 2011. 
Mühlbacher, H., Hemetsberger, A., Thelen, E., Vallaster, C., Massimo, R., Füller, J., Pirker, C., Schorn, R., \& Kittinger, C. (2006). Brand as complex social phenomena. Proceedings of the Thought Leaders International Conference on Brand Management, Birmingham.

Oliveira, J. C. (2005). Comunicação corporativa estratégica: um estudo de caso da Rede Globo de Televisão. Dissertação (Mestrado em Administração), UFRJ - Instituto COPPEAD de Administração, Rio de Janeiro.

Ouwersloot, H, \& Schröder, G. O. (2008). Who's who in brand communities - and why? European Journal of Marketing, 42(5/6), 571-585.

Piacentini, M. G., \& Banister, E. N. (2009). Managing anti-consumption in an excessive drinking culture. Journal of Business Research, 62, 279-288.

Pinto, M. R., \& Santos, L. L. S. (2008, julho-dezembro). Em busca de uma trilha interpretativista para a pesqquisa do consumidor: uma proposta baseada na fenomenologia, na etnografia e na grounded theory. RAE-Eletrônica. 7(2), Art. 25.

Ritson, M., \& Dobscha, S. (1999). Marketing Heretics: Resistance is/is not futile. Advances in Consumer Research, 26, 159.

Scaraboto, D. (2006, Sep-Dic). Comunidades on-line como fonte de informação em marketing: reflexões sobre possibilidades e práticas. Revista de Economía Política de las Tecnologías de la Información y Comunicación , 8(3), 26-41.

Schau, H. J., \& Gilly, M. C. (2003, December). We are what we post? Self-presentation in personal web space. Journal of Consumer Research, 30, 385- 404.

Schröeder, C. S., Berger, L. M., \& Klering, L. R. (2007). Comunidades virtuais: ausência do pensar, transgressões e crimes no ciberespaço. In: XXXI Encontro Nacional da Associação Nacional de Pós-Graduação e Pesquisa em Administração (ENANPAD), Rio de Janeiro. Anais... Rio de Janeiro: Anpad.

Silva, C. R., Gobbi, B. C., \& Simão, A. A. (2005). O uso da análise de conteúdo como uma ferramenta para a pesquisa qualitativa: descrição e aplicação do método. Organizações Rurais Agroindustriais, 7(1), 70-81.

Stolterman, E., Croon, A., \& Agren, P. O. (1997). Virtual communities - why and how are they studied. Working paper. Recuperado em 16 agosto, 2009, de: http://www.informatik.umu.se/nlrg/whyhow.pdf

Tureta, C., Cunha, J. A. C., \& Rosa, A. R. (2008). A indústria cultural na tela da TV: reflexões sobre poder econômico e ideológico no Brasil. In V Encontro de Estudos Organizacionais da $A N P A D$, Belo Horizonte. Anais... Belo Horizonte: Anpad.

Valck, K. (2005). Virtual communities of consumption: networks of consumer knowledge and companionship. Ph D Thesis, Erasmus University Rotterdam,. ERIM PhD Series: Research in Management.

REMark - Revista Brasileira de Marketing, São Paulo, v. 10, n. 3, p. 84-105, set./dez. 2011. 
Valtersson, M. (1996). Virtual communities. Master Thesis at the Department of Informatics. Umeå University. Recuperado em 21 agosto, 2009, de: http://www.informatik.umu.se/nlrg/valter.html

\title{
CYBERACTIVISM AND VIRTUAL COMMUNITIES: A STUDY ON THE MOVEMENT ANTI-GLOBE
}

\begin{abstract}
Protests are arising within cyberspace and among them is resistance to brands and consumption. The Internet has increasingly become a forum where individual claims are no longer private and become public which mobilizes other consumers about practices and injustices caused by the organizations. This study is a qualitative study that analyzed the behavior and the reasons for resistance to Globo in virtual communities. Virtual communities dedicated to resistance to this organization are in the hundreds networking site Orkut. An investigation was conducted on five selected communities with the largest number of members. To accomplish this goal nethnography was chosen as a way of investigating the behavior of participants in these communities. The researchers immersed themselves in the communities to make observations in these communities and copy data from virtual forums. From the observations of interactions in communities and content analysis five reasons were identified for the resistance to the organization and cyber-activism.
\end{abstract}

Keywords: Resistance; Cyber-activsm; Virtual communities.

Data do recebimento do artigo: 08/07/2011

Data do aceite de publicação: 21/10/2011

REMark - Revista Brasileira de Marketing, São Paulo, v. 10, n. 3, p. 84-105, set./dez. 2011. 